\title{
Ex vivo activity of the ACT new components pyronaridine and piperaquine in comparison with conventional ACT drugs against isolates of Plasmodium falciparum
}

Aurélie Pascual ${ }^{1,2}$, Philippe Parola ${ }^{3}$, Françoise Benoit-Vical ${ }^{4}$, Fabrice Simon $^{5}$, Denis Malvy ${ }^{6}$, Stéphane Picot $^{7}$, Pascal Delaunay ${ }^{8}$, Didier Basset ${ }^{9}$, Danièle Maubon ${ }^{10}$, Bernard Faugère ${ }^{11}$, Guillaume Ménard ${ }^{12}$, Nathalie Bourgeois ${ }^{13}$, Claude Oeuvray ${ }^{14}$, Eric Didillon ${ }^{15}$, Christophe Rogier ${ }^{1}$ and Bruno Pradines ${ }^{1,2^{*}}$

\begin{abstract}
Background: The aim of the present work was to assess i) ex vivo activity of pyronaridine (PND) and piperaquine (PPQ), as new components of artemisinin-based combination therapy (ACT), to define susceptibility baseline, ii) their activities compared to other partner drugs, namely monodesethylamodiaquine (MDAQ), lumefantrine (LMF), mefloquine (MQ), artesunate (AS) and dihydroartemisinin (DHA) against 181 Plasmodium falciparum isolates from African countries, India and Thailand, and iii) in vitro cross-resistance with other quinoline drugs, chloroquine (CQ) or quinine (QN).
\end{abstract}

Methods: The susceptibility of the 181 P. falciparum isolates to the nine anti-malarial drugs was assessed using the standard 42 -hours ${ }^{3} \mathrm{H}$-hypoxanthine uptake inhibition method.

Results: The $I_{50}$ values for PND ranged from 0.55 to $80.0 \mathrm{nM}$ (geometric mean $=19.9 \mathrm{nM}$ ) and from 11.8 to 217.3 $\mathrm{nM}$ for $\mathrm{PPQ}$ (geometric mean $=66.8 \mathrm{nM}$ ). A significant positive correlation was shown between responses to PPQ and PND responses $(r h o=0.46)$ and between PPQ and MDAQ $(r h o=0.30)$. No significant correlation was shown between PPQ $I_{50}$ and responses to other anti-malarial drugs. A significant positive correlation was shown between responses to PND and MDAQ (rho $=0.37)$, PND and LMF (rho $=0.28)$, PND and QN (rho $=0.24)$, PND and AS (rho $=0.19)$, PND and DHA (rho $=0.18)$ and PND and CQ $(r h o=0.16)$. All these coefficients of correlation are too low to suggest cross-resistance between PPQ or PND and the other drugs.

Conclusions: In this study, the excellent anti-malarial activity of PPQ and PND was confirmed. The absence of cross-resistance with quinolines and artemisinin derivatives is consistent with the efficacy of the combinations of PPQ and DHA or PND and AS in areas where parasites are resistant to conventional anti-malarial drugs.

Keywords: Malaria, Plasmodium falciparum, Anti-malarial, In vitro, Resistance, Pyronaridine, Piperaquine

\section{Background}

During the past 20 years, many strains of Plasmodium falciparum have become resistant to chloroquine and other anti-malarial drugs [1]. This has prompted a search for an effective alternative anti-malarial drug

\footnotetext{
* Correspondence: bruno.pradines@free.fr

'Unité de Recherche en Biologie et Epidémiologie Parasitaires Unité de Recherche pour les Maladies Infectieuses et Tropicales Emergentes UMR6236, Institut de Recherche Biomédicale des Armées, Allée du Médecincolonel Jamot,-BP 60109, 13262 Marseille Cedex, France

Full list of author information is available at the end of the article
}

with minimal side effects. The emergence and spread of parasites resistant to anti-malarial drugs has caused an urgent need for novel compounds to be discovered and developed. One strategy for reducing the prevalence of malaria is the combinatorial use of drugs. The combination protects each drug from the development of resistance and reduces the overall transmission of malaria [2]. The official first-line anti-malarial policy is now artemisinin-based combination therapy (ACT) [3]. The artemisinin derivative causes rapid and effective reduction of the parasite biomass and gametocytes carriage, 
while the partner drug, which has a longer duration of action, achieves effective clinical and parasitological cure. Different formulations of ACT were evaluated: artesunate-sulphadoxine-pyrimethamine [4], artesunateamodiaquine [5], artemether-lumefantrine [6], artesunate-mefloquine [7], artesunate-chlorproguanil-dapsone [8], dihydroartemisinin-piperaquine [9] and artesunatepyronaridine [10].

However, suspected decreased susceptibility of ACT or, at least, longer parasite clearance times have been described in Cambodia [11-14]. In addition, prior therapy by amodiaquine-containing $\mathrm{ACT}$ selected reduced response to monodesethylamodiaquine, suggested that amodiaquine-containing regimens may rapidly lose efficacy in Africa [15]. This emergence of parasite resistance to ACT indicates that novel compounds and combinations need to be discovered and developed.

The aim of the present work was to assess i) ex vivo activity of two recent ACT partner drugs, pyronaridine (PND) and piperaquine (PPQ) to define the susceptibility baseline, ii) comparison with standard components of ACT, such as monodesethylamodiaquine (the active metabolite of amodiaquine) (MDAQ), lumefantrine (LMF), mefloquine (MQ), artesunate (AS) or dihydroartemisinin (DHA), and iii) in vitro cross-resistance with other quinoline drugs, such as chloroquine $(\mathrm{CQ})$ and quinine $(\mathrm{QN})$.

\section{Methods}

\section{Plasmodium falciparum isolates}

In total, $181 \mathrm{P}$. falciparum isolates were collected between April 2008 and April 2010 from patients hospitalized in France with imported malaria from a malariaendemic country (Angola, Benin, Burkina Faso, Cameroon, Comoros, Congo, Ivory Coast, Gabon, Gambia, Ghana, Guinea, India, Madagascar, Mali, Mozambique, Niger, Central African Republic, Senegal, Thailand, Togo, Zambia). Informed consent was not required for this study as the sampling procedures and testing are part of the French national recommendations for the care and surveillance of malaria. Venous blood samples were collected in Vacutainer ${ }^{\circledR}$ ACD tubes (Becton Dickinson, Rutherford, NJ, USA) before treatment and transported at $4^{\circ} \mathrm{C}$ from French hospitals located in Marseille, Toulouse, Bordeaux, Lyon, Montpellier, Nice, Toulon, Nimes or Grenoble, to the Institute of Biomedical Research of the French Army (IRBA) in Marseille within less than 72 hours of collection. The Case Report Form was provided at the same time as a paper copy or electronically.

Thin blood smears were stained using a $\mathrm{RAL}^{\circledR}$ kit (Réactifs RAL, Paris, France) and examined to determine the $P$. falciparum density and to confirm monoinfection. Parasitized erythrocytes were washed three times in
RPMI 1640 medium (Invitrogen, Paisley, UK), buffered with $25 \mathrm{mM}$ HEPES and $25 \mathrm{mM} \mathrm{NaHCO}$. If parasitaemia exceeded $0.8 \%$, infected

erythrocytes were diluted to $0.5-0.8 \%$ with uninfected erythrocytes (human blood type $\mathrm{A}+$ ) and re-suspended in RPMI 1640 medium supplemented with $10 \%$ human serum (Abcys S.A. Paris, France) to a haematocrit of $1.5 \%$.

\section{Drugs}

PPQ, PND, DHA and AS were obtained from Shin Poong Pharm Co. (Seoul, Korea). CQ and QN were purchased from Sigma (Saint Louis, MO). MDAQ was obtained from the World Health Organization (Geneva, Switzerland), MQ from Roche (Paris, France) and LMF from Novartis Pharma (Basel, Switzerland). PPQ, QN, MDAQ, MQ, DHA and AS were dissolved first in methanol and then diluted in water to obtain final concentration ranging from 0.8 to $1,000 \mathrm{nM}$ for $\mathrm{PPQ}, 5$ to $3,200 \mathrm{nM}$ for QN, 1.56 to $1,000 \mathrm{nM}$ for MDAQ, 3.2 to $400 \mathrm{nM}$ for MQ and 0.1 to $100 \mathrm{nM}$ for DHA and AS. PND and CQ were dissolved and diluted in water in concentrations ranging between 0.15 to $100 \mathrm{nM}$ for PND, 5 to $3,200 \mathrm{nM}$ for CQ. LMF was dissolved and diluted in ethanol to obtain final concentration ranging from 0.5 to $310 \mathrm{nM}$.

\section{Ex vivo assay}

The new term 'ex vivo susceptibility' is used to describe studies on fresh isolates, while the term of 'in vitro susceptibility' should now refer to studies on strains of parasites, which have been either kept in culture for at least two to three generations or which have been cryo-preserved. For ex vivo isotopic microtests, $200 \mu \mathrm{l} /$ well of the suspension of synchronous parasitized red blood cells (final parasitaemia, 0.5\%; final haematocrit, $1.5 \%$ ) were distributed in 96 -well plates pre-dosed with anti-malarial drugs. Parasite growth was assessed by adding $1 \mu \mathrm{Ci}$ of tritiated hypoxanthine with a specific activity of $14.1 \mathrm{Ci} / \mathrm{mmol}$ (Perkin-Elmer, Courtaboeuf, France) to each well at time zero. The plates were then incubated for 42 hours in controlled atmospheric conditions that consisted of $10 \% \mathrm{O}_{2}, 5 \%$ $\mathrm{CO}_{2}$, and $85 \% \mathrm{~N}_{2}$ at $37^{\circ} \mathrm{C}$ with a humidity of $95 \%$. Immediately after incubation, plates were frozen and then thawed to lyse erythrocytes. The content of each well was collected on standard filter microplates (Unifilter GF/B; Perkin-Elmer) and washed using a cell harvester (Filter-Mate Cell Harvester; Perkin-Elmer). Filter microplates were dried, and $25 \mu$ lof scintillation cocktail (Microscint O; Perkin-Elmer) was placed in each well. Radioactivity incorporated in nucleotides by the parasites was measured with a scintillation counter (Top Count; Perkin-Elmer). 
Internal controls were used (testing of 3D7 and W2 P. falciparum clones maintained in continuous culture) in order to validate the results. All strains were synchronized twice with sorbitol before use [16].

Clonality was verified using PCR genotyping of polymorphic genetic markers $m s p 1, m s p 2$, and microsatellite loci $[17,18]$.

The drug concentration that inhibits $50 \%$ of parasite growth $\left(\mathrm{IC}_{50}\right)$ was defined as the drug concentration corresponding to $50 \%$ of the incorporation of tritiated hypoxanthine by the parasite in the drug-free control wells. The $\mathrm{IC}_{50}$ value was determined by non-linear regression analysis of log-based dose-response curves (Riasmart ${ }^{\mathrm{TM}}$, Packard, Meriden, USA).

\section{Statistical analysis}

Data of ex vivo susceptibility of P. falciparum parasites were analysed after logarithmic transformation and expressed as the geometric mean of the $\mathrm{IC}_{50}$ and the 95\% confidence interval (95\% CI). Cross-resistance between the nine drugs was assessed by a pair-wise correlation of $\mathrm{IC}_{50}$ values of all isolates and estimated by coefficient of correlation of Spearman (rho) (non-parametric test), coefficient of correlation of Pearson $(r)$ (parametric test) and coefficient of determination $\left(r^{2}\right)$.

\section{Results}

One hundred and eighty one $P$. falciparum isolates were tested for their ex vivo susceptibility to PPQ, PND, CQ, $\mathrm{QN}, \mathrm{MQ}, \mathrm{MDAQ}, \mathrm{LMF}, \mathrm{DHA}$ and AS. The mean $\mathrm{IC}_{50} \mathrm{~S}$ for these nine anti-malarial drugs are presented in Table 1. The $\mathrm{IC}_{50}$ values for PND ranged from 0.55 to 80.0 $\mathrm{nM}$ (geometric mean $=19.9 \mathrm{nM}, 95 \%=$ CI 18.0-022.0) and from 11.8 to $217.3 \mathrm{nM}$ for PPQ (geometric mean = $66.8 \mathrm{nM}, 95 \% \mathrm{CI}=61.8-72.3)$. The distributions of the $\mathrm{IC}_{50}$ for the nine anti-malarial drugs are presented in Figure 1.
In vitro cross-resistance was measured by pair-wise correlation of $\mathrm{IC}_{50}$ values of 181 isolates (Table 2). A significant positive correlation was shown between responses to PPQ and PND responses (rho $=0.46 ; P<$ $0.00001)$ and between PPQ and MDAQ (rho $=0.30 ; P=$ $0.0001)$. No significant correlation was shown between PPQ $\mathrm{IC}_{50}$ and responses to other anti-malarial drugs. A significant positive correlation was shown between responses to PND and MDAQ (rho $=0.37 ; P<$ $0.00001)$, LMF ( $r h o=0.28 ; P=0.0002)$, QN $(r h o=0.24$; $P=0.0012)$, AS (rho $=0.19 ; P=0.0108)$, DHA (rho $=$ $0.18 ; P=0.0173)$ and CQ (rho $=0.16 ; P=0.0365)$. The highest coefficients of correlation were shown for correlation between responses to DHA and AS (rho $=0.84 ; P$ $<0.00001)$, LMF and MQ (rho $=0.58 ; P<0.00001)$, CQ and MDAQ ( $r h o=0.51 ; P<0.00001)$, LMF and DHA (rho $=0.46 ; P<0.00001)$, LMF and AS (rho $=0.45 ; P<$ $0.00001)$ or $\mathrm{CQ}$ and $\mathrm{QN}$ (rho $=0.41 ; P<0.00001)$.

Isolates with high $\mathrm{IC}_{50}$ to at least one of the antimalarial drug are listed in Table 3. One originated from Thailand with $\mathrm{IC}_{50}=71.5 \mathrm{nM}$ for PND associated with $\mathrm{IC} 50=91.1 \mathrm{nM}$ for PPQ, IC50 $=1,131 \mathrm{nM}$ for $\mathrm{QN}$, IC50 $=166 \mathrm{nM}$ for MQ, IC50 = 114 nM for LMF, IC50 $=21.2 \mathrm{nM}$ for DHA and IC50 $=16.3 \mathrm{nM}$ for AS.

\section{Discussion}

Ex vivo analysis of the susceptibility of $P$. falciparum isolates to anti-malarial drugs has three important attributes. This approach allows firstly to assay the response of clinical isolates to individual drugs that are unmodified by important host factors that influence drug efficacy in vivo. Secondly, the progressive decline in drug susceptibility of isolates from the same site may identify incipient resistance in the parasite population. Finally, strains with reduced anti-malarial susceptibilities can then be established in continuous culture to provide the material needed to investigate novel molecular

Table 1 Ex vivo susceptibility of the 181 isolates of Plasmodium falciparum to pyronaridine (PND), piperaquine (PPQ), chloroquine (CQ), quinine (QN), mefloquine (MQ), monodesethylamodiaquine (MDAQ), lumefantrine (LMF), dihydroartemisinin (DHA) and artesunate (AS)

\begin{tabular}{|c|c|c|c|c|c|c|c|c|}
\hline \multirow[b]{2}{*}{ Drugs } & \multicolumn{2}{|r|}{$\mathrm{IC}_{50}$ in $\mathrm{nM}$} & \multirow[b]{2}{*}{ 95\% Confidence Interval } & \multirow[b]{2}{*}{$\min$} & \multirow[b]{2}{*}{ Q25 } & \multirow[b]{2}{*}{ median } & \multirow[b]{2}{*}{ Q75 } & \multirow[b]{2}{*}{$\max$} \\
\hline & No & geometric mean & & & & & & \\
\hline PND & 176 & 19.9 & $18.0-22.0$ & 0.55 & 15.0 & 19.4 & 32.1 & 80.0 \\
\hline PPQ & 179 & 66.8 & $61.8-72.3$ & 11.8 & 48.0 & 76.7 & 90.5 & 217.3 \\
\hline CQ & 181 & 79.8 & $66.6-95.6$ & 5.0 & 22.9 & 96.0 & 246.0 & 1918.0 \\
\hline QN & 181 & 254.6 & $234.7-276.1$ & 54.8 & 182.0 & 265.0 & 358.0 & 1131.0 \\
\hline MQ & 181 & 15.5 & $13.6-17.6$ & 3.0 & 8.9 & 15.8 & 29.7 & 166.0 \\
\hline MDAQ & 181 & 22.1 & $19.1-25.6$ & 1.5 & 11.8 & 22.6 & 43.3 & 240.0 \\
\hline LMF & 181 & 7.3 & $6.1-8.8$ & 0.25 & 5.5 & 8.0 & 17.7 & 114.0 \\
\hline DHA & 181 & 1.3 & $1.2-1.5$ & 0.10 & 0.9 & 1.4 & 2.4 & 21.2 \\
\hline AS & 179 & 1.1 & $1.0-1.3$ & 0.10 & 0.7 & 1.3 & 2.1 & 20.6 \\
\hline
\end{tabular}

Min: $I C_{50}$ minimum Max: $I C_{50}$ maximun Q25: $1^{\text {st }}$ quartile Q75: $3^{\text {rd }}$ quartile 


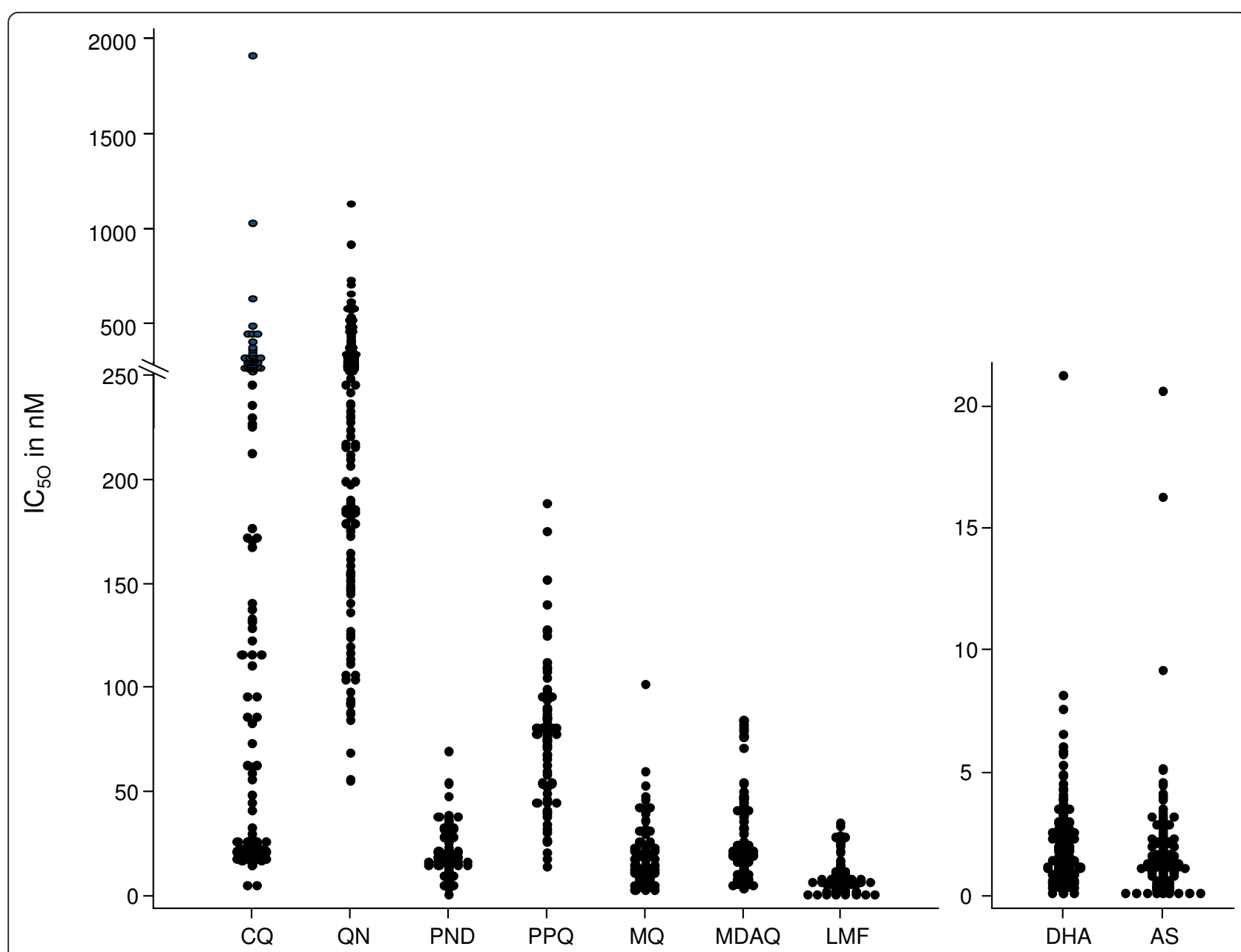

Figure 1 Dot plots of $I C_{50}$ values in $n M$ for chloroquine $(C Q)$, quinine $(Q N)$, pyronaridine (PND), piperaquine (PPQ), mefloquine (MQ), monodesethylamodiaquine (MDAQ), lumefantrine (LMF), dihydroartemisinin (DHA) and artesunate (AS). Each dot represents one isolate.

mechanisms of resistance as well as for tests of susceptibility to other anti-malarial agents.

The continued spread of $P$. falciparum drug resistance to monotherapies has forced a shift toward the use of ACT. Nevertheless, resistance to at least one component of many of the different formulations of ACT currently in clinical use has been documented, and it is feared that the widespread use of ACT will gradually reduce its clinical efficacy. Clinical failures or at least longer parasite clearance times have been described in Cambodia [12]. In addition, prior therapy by amodiaquine-containing ACT selected reduced response to monodesethylamodiaquine, suggested that amodiaquine-containing regimens may rapidly lose efficacy in Africa [15].

One hundred and eighty one P. falciparum strains were tested for their in vitro susceptibility to PPQ, PND, $\mathrm{CQ}, \mathrm{QN}, \mathrm{MQ}, \mathrm{MDAQ}, \mathrm{LMF}, \mathrm{DHA}$ and $\mathrm{AS}$. The $\mathrm{IC}_{50}$ values for PND ranged from 0.55 to $80.0 \mathrm{nM}$ (geometric mean $=19.9 \mathrm{nM}, 95 \% \mathrm{CI}=18.0-22.0)$. These values are in accordance with previous studies on $P$. falciparum strains (1.9-47.8 $\mathrm{nM}$ and 15-49 $\mathrm{nM}$, respectively) [19,20] or in isolates from patients in Thailand cured with PND (geometric mean $=15.7 \mathrm{nM}$ ) or that recrudesced after PND treatment (geometric mean $=23.0 \mathrm{nM}$ ) [21] but higher than those found in isolates from Cameroon (geometric mean $=3.58 \mathrm{nM}$ ), Senegal (geometric mean $=3.8 \mathrm{nM}$ and $4.52 \mathrm{nM}$ ), Gabon (geometric mean $=3.0$ $\mathrm{nM}$ and $1.87 \mathrm{nM}$ ) [22-26] and in Indonesia (geometric mean $=1.92 \mathrm{nM}$ ) [27]. In addition, PND is also effective in vitro against Plasmodium vivax isolates (geometric mean $=2.58 \mathrm{nM}$ ) [27].

Antagonistic in vitro drug interactions between PND and artemisinin derivatives have been described $[22,28,29]$. Previous studies have demonstrated in vitro cross-resistance between PND and DHA or CQ, with coefficients of determination $\left(r^{2}\right)$ of 0.84 and 0.19-0.46, respectively [19,21,23-25]. A low $r^{2}(0.20)$ was determined between PND and AS in P. falciparum strains 
Table 2 Spearman correlation (rho) and Pearson correlation $\left(r^{2}\right)$ of in vitro responses of 181 isolates of Plasmodium falciparum to pyronaridine (PND), piperaquine (PPQ), chloroquine (CQ), quinine (QN), mefloquine (MQ), monodesethylamodiaquine (MDAQ), lumefantrine (LMF), dihydroartemisinin (DHA) and artesunate (AS)

\begin{tabular}{|c|c|c|c|c|c|c|c|c|c|}
\hline & & $\mathrm{CQ}$ & QN & MQ & DHA & AS & MDAQ & LMF & PND \\
\hline \multirow[t]{3}{*}{ QN } & Rho & 0,4143 & & & & & & & \\
\hline & $p$-value & $<0,00001$ & & & & & & & \\
\hline & $r^{2}$ & 0.159 & & & & & & & \\
\hline \multirow[t]{3}{*}{ MQ } & Rho & $-0,1254$ & 0,1139 & & & & & & \\
\hline & $p$-value & 0,0936 & 0,128 & & & & & & \\
\hline & $r^{2}$ & 0.020 & 0.008 & & & & & & \\
\hline \multirow[t]{3}{*}{$\mathrm{DHA}$} & Rho & $-0,1471$ & 0,134 & 0,3164 & & & & & \\
\hline & $p$-value & 0,0488 & 0,0729 & $<0,00001$ & & & & & \\
\hline & $r^{2}$ & 0.026 & 0.020 & 0.109 & & & & & \\
\hline \multirow[t]{3}{*}{ AS } & Rho & $-0,1196$ & 0,1291 & 0,364 & 0,8374 & & & & \\
\hline & $p$-value & 0,1109 & 0,0851 & $<0,00001$ & $<0,00001$ & & & & \\
\hline & $r^{2}$ & 0.013 & 0.013 & 0.124 & 0.681 & & & & \\
\hline \multirow[t]{3}{*}{ MDAQ } & Rho & 0,5071 & 0,0997 & $-0,115$ & $-0,1615$ & $-0,0769$ & & & \\
\hline & $p$-value & $<0,000010,1831$ & 0,1243 & 0,0303 & 0,3074 & & & & \\
\hline & $r^{2}$ & 0.227 & 0.012 & 0.014 & 0.028 & 0.005 & & & \\
\hline \multirow[t]{3}{*}{ LMF } & Rho & $-0,1799$ & 0,126 & 0,5821 & 0,4636 & 0,4533 & $-0,1451$ & & \\
\hline & $p$-value & 0,0156 & 0,0918 & $<0,00001$ & $<0,00001$ & $<0,00001$ & 0,0519 & & \\
\hline & $r^{2}$ & 0.030 & 0.014 & 0.300 & 0.189 & 0.163 & 0.012 & & \\
\hline \multirow[t]{3}{*}{ PND } & Rho & 0,1582 & 0,2425 & 0,0711 & 0,1798 & 0,1933 & 0,3658 & 0,2776 & \\
\hline & $p$-value & 0,0365 & 0,0012 & 0,3496 & 0,0173 & 0,0108 & $<0,00001$ & 0,0002 & \\
\hline & $r^{2}$ & 0.017 & 0.060 & 0.003 & 0.027 & 0.038 & 0.101 & 0.082 & \\
\hline \multirow[t]{3}{*}{ PPQ } & Rho & 0,036 & 0,0478 & $-0,0203$ & $-0,0766$ & $-0,06$ & 0,2988 & 0,1234 & 0,4672 \\
\hline & $p$-value & 0,6336 & 0,5263 & 0,7881 & 0,3094 & 0,4288 & 0,0001 & 0,1007 & $<0,00001$ \\
\hline & $r^{2}$ & $<0.001$ & 0.002 & $<0.001$ & 0.001 & 0.001 & 0.096 & 0.029 & 0.230 \\
\hline
\end{tabular}

Table 3 Isolates with high $I_{50}$ to at least one anti-malarial drug among the 181 isolates tested

\begin{tabular}{|c|c|c|c|c|c|c|c|c|c|}
\hline \multirow{2}{*}{$\begin{array}{l}\text { Isolates } \\
\text { origin }\end{array}$} & \multicolumn{9}{|c|}{$I C_{50}$ in $\mathrm{nM}$} \\
\hline & PND & PPQ & CQ & QN & MQ & MDAQ & LMF & DHA & AS \\
\hline$\overline{\text { Mali }}$ & ND & 175 & 22 & 185 & 23.4 & 44.8 & 25.8 & 1.2 & 2.0 \\
\hline Comoros & ND & 177.5 & 130 & 460 & 27.6 & 76.4 & 15.8 & 1.2 & 3.2 \\
\hline Cameroon & 15.0 & 189 & 171 & 217 & 8.0 & 16.3 & 7.0 & 2.0 & 1.9 \\
\hline Africa & 28.4 & 217.3 & 1029 & 580 & 31.3 & 240.0 & 17.7 & 1.6 & 1.3 \\
\hline Côte d'Ivoire & 31.2 & 172.8 & 60 & 377 & 68.0 & 4.6 & 58.0 & 5.3 & 4.0 \\
\hline Comoros & 34.2 & 83.8 & 108 & 707 & 4.4 & 40.5 & 20.7 & 3.3 & 2.9 \\
\hline Gabon & 37.2 & 90.2 & 1918 & 580 & 40.7 & 42.8 & 25.1 & 3.4 & 2.9 \\
\hline Comoros & 36.1 & 214 & 145 & 292 & 15.8 & 69.3 & 8.1 & 1.1 & 1.4 \\
\hline Cameroon & 40.2 & 181.6 & 444 & 576 & 3.2 & 171 & 5.4 & 0.8 & 0.6 \\
\hline Comoros & 66.0 & 60.2 & 304 & 176 & 18.5 & 78.9 & 13.1 & 3.5 & 4.6 \\
\hline Niger & 66.3 & 79.9 & 331 & 393 & 37.4 & 61.0 & 20.1 & 0.7 & 0.5 \\
\hline Comoros & 66.7 & 82.6 & 244 & 918 & 3.5 & 46.6 & 14.1 & 0.8 & 0.8 \\
\hline Benin & 67.4 & 82.4 & 17 & 728 & 5.3 & 21.7 & 36.4 & 3.0 & 2.2 \\
\hline Comoros & 69.4 & 46.0 & 246 & 210 & 5.3 & 82.4 & 6.4 & 1.9 & 1.9 \\
\hline Thailand & 71.5 & 91.1 & 63 & 1131 & 166 & 34.4 & 114.0 & 21.2 & 16.3 \\
\hline Côte d'Ivoire & 76.1 & 91.0 & 288 & 660 & 7.8 & 56.0 & 1.4 & 1.3 & 1.8 \\
\hline Comoros & 80.0 & 82.0 & 321 & 587 & 32.9 & 47.2 & 6.7 & 2.5 & 3.5 \\
\hline
\end{tabular}

High $\mathrm{IC}_{50}$ s are in bold

ND: not determined 
[20]. In the present study, a positive correlation was shown between PND and DHA or AS responses with a coefficient of correlation rho $=0.18$ and 0.19 , respectively. To suggest common mechanisms of action or resistance for two compounds, that could induce crossresistance, the coefficient of determination must be high, such as the one for AS and DHA (rho $=0.84$ and $\left.r^{2}=0.68\right)$ corresponding to $68 \%$ of the variation in the response to DHA is explained by variation in the response to AS. A coefficient of determination of 0.027 or 0.038 means that only $2.7 \%$ and $3.8 \%$ of the variation in the response to PND is explained by variation in the response to DHA and AS. These data suggest that there is no cross-resistance between PND and artemisinin derivatives. In addition, the combination of PND and AS has undergone successful clinical evaluation in Africa $[10,30]$. In the present study, a positive correlation was shown between PND and CQ responses with a coefficient of correlation $r h o=0.16$ and $r^{2}=0.017$. This means that only $1.7 \%$ of the variation in the response to PND is explained by variation in the response to CQ. These data are consistent with the efficacy of the combination of PND and AS for areas in which parasites are resistant to CQ [10,30]. There have been conflicting reports on the correlations between $P$. falciparum responses to PND and CQ. Previous studies showed weak (from 0.003 to 0.26$)$ [20,23-25,27] to modest $(0.40$ and 0.46$)[19,21]$ coefficients of determination for correlations between PND and CQ. PND appeared to be equally effective in vitro against 37 isolates from two areas of Thailand with different CQ resistance levels [31]. Similarly, Basco and Le Bras showed no correlation between resistance to PND and CQ for 31 isolates from Central and West Africa [32]. These results suggest that no cross-resistance exists between PND and CQ. In addition, an isolate collected in a patient who took part in trekking along the Mekong from the south of Laos to the north of Thailand showed high susceptibility to CQ and MDAQ and very low susceptibility to PND (71.5 $n M)$, PPQ (91.1 nM), QN (1,131 nM), MQ (166 nM), LMF (114 $\mathrm{nM})$ and to the artemisinin derivatives DHA (21.2 $\mathrm{nM})$ and AS (16.3 nM) [33]. This multi-resistant isolate was suspected of being resistant to ACT. All of the other significant positive correlations between PND and QN, MDAQ or LMF are too low (rho $<0.37, r^{2}<$ $0.10)$ to suggest cross-resistance between PND and quinoline drugs. This absence of cross-resistance may be explained by the absence of association between PND and genes involved in quinoline resistance, such as $p f c r t$, pfmdr1, pfmrp or pfnhe-1 [20].

The highest coefficient of correlation was observed between PND and PPQ (rho $=0.47$ and $r^{2}=0.23$ ). This means that $23 \%$ of the variation in the response to PND is explained by variation in the response to PPQ. This result is also too low to suggest cross-resistance between the two drugs. This result was in accordance with previous data $\left(r^{2}=0.20\right)$ [27].

In vitro drug interaction between PPQ and artemisinin derivatives was indifferent or antagonistic [34-37]. However, PPQ has been combined with DHA and it has undergone successful clinical evaluation in Africa, Asia and South America [9,38-40]. In addition, PPQ-DHA is also effective to treat $P$. vivax malaria [41]. But unfortunately clinical failures to PPQ have been reported in areas of China where it has been deployed in monotherapy for $P$. falciparum [42].

The $\mathrm{IC}_{50}$ values for PPQ ranged from 11.8 to 217.3 $\mathrm{nM}$ (geometric mean $=66.8 \mathrm{nM}, \mathrm{CI} 95 \% 61.8-72.3$ ). These data are in accordance with previous studies on P. falciparum strains $[35,43]$ or isolates from Cameroon (geometric mean $=39 \mathrm{nM}$ ) [44], Thai-Burmese border (49 nM) [45] and Kenya (50 nM) [46], but superior to geometric mean of isolates from Uganda $(6.1 \mathrm{nM})$ [47], Indonesia (21.8 nM) [48] or Papua New Guinea [49]. The isolate with the highest $\mathrm{IC}_{50}$ to PPQ $(217.3 \mathrm{nM})$ was also resistant to CQ (1029 nM) and MDAQ (240 $\mathrm{nM})$.

Encouragingly, PPQ has not shown any correlation with the other quinoline drugs, i.e. $\mathrm{CQ}, \mathrm{QN}, \mathrm{MDAQ}$, LMF or MQ. These results suggest that no cross-resistance exists between PPQ and CQ and the other quinoline anti-malarial drugs. These data are in accordance with previous studies, which showed weak coefficients of determination included between 0.015 and 0.14 for correlation between PPQ and CQ [43,45-47]. No significant correlation was identified between PPQ and DHA or AS. These data are in accordance with previous results [47]. PPQ has shown no cross-resistance with any of the anti-malarial drug tested. The absence of cross-resistance may be explained by the absence of association between PPQ and genes involved in quinoline resistance, such as $p f c r t, p f m d r 1, p f m r p$ or $p f n h e-1$ [43]. A copy number variation event on chromosome 5 could be associated with PPQ resistance [50]. Transgene expression studies are underway with individual genes in this segment to evaluate their contribution to PPQ resistance.

DHA-PPQ is an inexpensive, safe and highly effective treatment for uncomplicated falciparum and vivax malaria $[41,51,52]$. DHA-PPQ seems to offer a better post-treatment prophylactic effect following therapy compared with artemether-LMF $[6,53,54]$ or AS-amodiaquine [55]. The significant lower risk of recurrent parasitaemia after treatment with DHA-PPQ is likely to be explained by differences in pharmacokinetics of the non-artemisinin partner drugs. PPQ, a bisquinoline, is estimated to have elimination half-life of 17-33 days $[38,56,57]$ while LMF and MDAQ have an estimated 
elimination half-life of two to six days and one-10 days [58], respectively.

The PND-AS combination $\left(\right.$ Pyramax $^{\circledR}$ ) is one of the latest ACT combinations currently under development by the not-for-profit organisation Medicines for Malaria Venture (Geneva, Switzerland) and the pharmaceutical company Shin Poong Pharmaceuticals (Seoul, Republic of Korea) for the treatment of uncomplicated P. falciparum malaria and for the blood stages of $P$. vivax malaria. Pyramax ${ }^{\circledR}$ has recently completed phase III trials in humans. A five-day regimen of PND alone (total dose $=1800 \mathrm{mg}$ ) produced a better cure rate than AS, artemether or MQ used alone in the same conditions in Thailand [21]. Efficacy of PND-AS was noninferior to that of artemether-LMF for treatment of uncomplicated falciparum malaria in Africa and Southeast Asia [10].

\section{Conclusions}

In this study, the excellent in vitro anti-malarial activities of the ACT components PPQ and PND on P. falciparum were confirmed. The absence of cross-resistance with quinolines and artemisinin derivatives confirmed the relevant use of the combinations of PPQ and DHA or PND and AS in areas where parasites are resistant to conventional anti-malarial drugs.

\section{Acknowledgements}

The authors thank R Amalvict, E Baret, S Charras from IRBA for technical support. This work was supported by the Direction Centrale du Service de Santé des Armées, the Institut de Veille Sanitaire and Medicines for Malaria Venture.

\section{Author details}

'Unité de Recherche en Biologie et Epidémiologie Parasitaires Unité de Recherche pour les Maladies Infectieuses et Tropicales Emergentes UMR6236, Institut de Recherche Biomédicale des Armées, Allée du Médecincolonel Jamot,-BP 60109, 13262 Marseille Cedex, France. ${ }^{2}$ Centre National de Référence du Paludisme, Marseille, France. ${ }^{3}$ Institut Hospitalo-Universitaire en Maladies Infectieuses et Tropicales, Hôpital Nord, Marseille, France.

${ }^{4}$ Laboratoire de Parasitologie-Mycologie, Centre Hospitalier Universitaire de Ranqueil, Toulouse, France. ${ }^{5}$ Service de Pathologie Infectieuse et Tropicale, Hôpital d'Instruction des Armées Laveran, Marseille, Frnace. ${ }^{6}$ Travel Clinics and Division of Tropical Medicine and Imported Diseases, Centre Hospitalier Universitaire, Bordeaux, France. ${ }^{7}$ Malaria Research Unit, UMR 5246, CNRS Lyon, France. ${ }^{8}$ Laboratoire de Parasitologie-Mycologie, Hopital de 1'Archet, Nice, France. ' ${ }^{\circ}$ Laboratoire de Parasitologie-Mycologie, Centre Hospitalier Universitaire Lapeyronnie, Montpellier, France. ${ }^{10}$ Laboratoire de ParasitologieMycologie, Centre Hospitalier Universitaire et Université de Grenoble 1 , Grenoble, France. " ${ }^{11}$ Laboratoire de Parasitologie-Mycologie, Centre Hospitalier Universitaire La Timone, Marseille, France. ${ }^{12}$ Fédération des Laboratoires, Hôpital d'Instruction des Armées Sainte Anne, Toulon, France. ${ }^{13}$ Service de Bactériologie-Virologie-Parasitologie, Centre Hospitalier Universitaire Caremeau, Nimes, France. ${ }^{14}$ Medicines for Malaria Venture, Geneva, Switzerland. ${ }^{15}$ Fulcrum Pharma (Europe) Ltd, Hemel Hempstead, UK.

\section{Authors' contributions}

$\mathrm{AP}, \mathrm{CR}$ and $\mathrm{BP}$ conceived, designed, carried out in vitro testing of drug susceptibility, analysed the data and drafted the manuscript. PP, FBV, FS, DM, $\mathrm{SP}, \mathrm{PD}, \mathrm{DB}, \mathrm{DM}, \mathrm{BF}, \mathrm{GM}$ and $\mathrm{NB}$ carried out diagnostic, monitoring patients, collected clinical and epidemiological data. CO and ED conceived, designed and drafted the manuscript. All authors read and approved the final manuscript.

\section{Competing interests}

The authors declare that they have no competing interests. The conclusions presented in this article were not financially influenced.

Received: 17 October 2011 Accepted: 14 February 2012

Published: 14 February 2012

\section{References}

1. Le Bras J, Musset L, Clain J: Antimalarial drug resistance. Med Mal Infect 2006, 36:401-405.

2. White NJ: Preventing antimalarial drug resistance through combinations. Drug Resist Update 2001, 1:3-9.

3. Eastman RT, Fidock DA: Artemisinin-based combination therapies: a vital tool in efforts to eliminate malaria. Nat Rev Microbiol 2009, 7:864-874.

4. Von Seidlein L, Milligan P, Pinder M, Bojang K, Anyalebechi C, Gosling R, Coleman R, Ude JI, Sadiq A, Duraisingh M, Warhurst D, Alloueche A, Target G, Mcadam K, Greenwood B, Walraven G, Olliaro P, Doherty T: Efficacy of artesunate plus pyrimethamine-sulphadoxine for uncomplicated malaria in the Gambian children: a double-blind, randomized, controlled trial. Lancet 2000, 355:352-357.

5. Brasseur P, Agnamey P, Gaye O, Vaillant M, Taylor WRJ, Olliaro PL: Efficacy and safety of artesunate plus amodiaquine in routine use for the treatment of uncomplicated malaria in Casamance, southern Senegal. Malar J 2007, 6:150.

6. Yeka A, Dorsey G, Kamya MR, Talisuna A, Lugemwa M, Rwakimari JB, Staedke SG, Rosenthal PJ, Wabwire-Mangen F, Bukirwa H: Artemetherlumefantrine versus dihydroartemisinin-piperaquine for treating uncomplicated malaria: a randomized trial to guide policy in Uganda. PLoS One 2008, 3:2390.

7. Ashley EA, Lwin KM, Mcgready R, Simon WH, Phaiphun L, Proux S, Wangseang N, Taylor W, Stepniewska K, Nawamaneerat W, Thwai KL, Barends M, Leowattana W, Olliaro P, Singhasivanon P, White NJ, Nosten F: An open label randomized comparison of mefloquine-artesunate as separate tablets vs. a new co-formulated combination for the treatment of uncomplicated multidrug-resistant falciparum malaria in Thailand. Trop Med Int Health 2006, 11:1653-1660.

8. Owusu-Agyei S, Asante KP, Owusu R, Adjuik M, Amenga-Etego S, Dosoo DK, Gyapong J, Greenwood B, Chandramohan D: An open label, randomised trial of artesunate + amodiaquine, artesunate + chlorproguanil-dapsone and artemether-lumefantrine for the treatment of uncomplicated malaria. PloS One 2008, 3:2530.

9. Arinaitwe E, Sandison TG, Wanzira H, Kahuru A, Homsy J, Kalamya J, Kamya MR, Vora N, Greenhouse B, Rosenthal PJ, Tappero J, Dorsey G: Artemether-lumefantrine versus dihydroartemisinin-piperaquine for falciparum malaria: a longitudinal, randomized trial in young Ugandan children. Clin Infect Dis 2009, 49:1629-1637.

10. Tshefu AK, Gaye O, Kayentao K, Thompson R, Bhatt KM, Sesay SSS, Bustos DG, Tjitra E, Bedu-Addo G, Borghini-Fuhrer I, Duparc S, Sik Shin C, Fleckenstein L: Efficacy and safety of a fixed-dose oral combination of pyronaridine-artesunate compared with artemether-lumefantrine in children and adults with uncomplicated Plasmodium falciparum malaria: a randomised non-inferiority trial. Lancet 2010, 375:1457-1467.

11. Carrara VI, Zwang J, Ashley EA, Price RN, Stepniewska K, Barends M, Brockman A, Anderson T, McGready R, Phaiphun L, Proux S, van Vugt M, Hutagalung R, Lwin KM, Phyo AP, Preechapornkul P, Imwong M, Pukrittayakamee S, Singhasivanon P, White NJ, Nosten F: Changes in the treatment responses to artesunate-mefloquine on the Northwestern border of Thailand during 13 years of continuous deployment. PloS One 2009, 4:4451.

12. Dondorp AM, Nosten F, Yi P, Das D, Phyo AP, Tarning J, Lwin KM, Ariey F, Hanpithakpong W, Lee SJ, Ringwald P, Silamut K, Imwrong M, Chotivanish K, Lim P, Herdman T, An SS, Yeung S, Singhasivanon P, Day NPJ, Lindegardh N, Socheat D, White NJ: Artemisinin resistance in Plasmodium falciparum malaria. N Engl J Med 2009, 361:455-467.

13. Noedl H, Se Y, Schaecher K, Smith BL, Socheat D, Fukuda MM: Evidence of artemisinin-resistant malaria in western Cambodia. N Engl J Med 2008, 359:2619-2620. 
14. Rogers WO, Sem R, Tero T, Chim P, Lim P, Muth S, Socheat D, Ariey F, Wongsrichanalai $C$ : Failure of artesunate-mefloquine combination therapy for uncomplicated Plasmodium falciparum malaria in southern Cambodia. Malar J 2009, 8:10.

15. Nawaz F, Nsobya SL, Kiggundu M, Joloba M, Rosenthal PJ: Selection of parasites with diminished drug susceptibility by amodiaquine-containing antimalarial regimens in Uganda. J Infect Dis 2009, 200:1650-1657.

16. Lambros C, Vanderberg JP: Synchronization of Plasmodium falciparum erythrocytic stages in culture. J Parasitol 1979, 65:418-420.

17. Bogreau H, Renaud F, Bouchiba H, Durand P, Assi SB, Henry MC, Garnotel E, Pradines B, Fusai T, Wade B, Adehossi E, Parola P, Kamil MA, Puijalon O, Rogier C: Genetic diversity and structure of African Plasmodium falciparum populations in urban and rural areas. Am J Trop Med Hyg 2006, 74:953-959.

18. Henry M, Diallo I, Bordes J, Ka S, Pradines B, Diatta B, M' Baye PS, Sane M, Thiam M, Gueye PM, Wade B, Touze JE, Debonne JM, Rogier C, Fusai T: Urban malaria in Dakar, Senegal: chemosusceptibility and genetic diversity of Plasmodium falciparum isolates. Am J Trop Med Hyg 2006, 75:146-151.

19. Elueze El, Croft SL, Warhurst DC: Activity of pyronaridine and mepacrine against twelve strains of Plasmodium falciparum in vitro. J Antimicrob Chemother 1996, 37:511-518.

20. Pradines B, Briolant S, Henry M, Oeuvray C, Baret E, Amalvict R, Didillon E, Rogier $C$ : Absence of association between pyronaridine in vitro responses and polymorphisms in genes involved in quinoline resistance in Plasmodium falciparum. Malar J 2010, 9:337.

21. Looareesuwan S, Kyle DE, Vivaran C, Vanijanonta S, Wilairatana P, Wernsdorfer $\mathrm{WH}$ : Clinical study of pyronaridine for the treatment of acute uncomplicated falciparum malaria in Thailand. Am J Trop Med Hyg 1996, 54:205-209.

22. Ringwald P, Moukoko Eboumbou CE, Bickii J, Basco LK: In vitro activities of pyronaridine, alone and in combination with other antimalarial drugs, against Plasmodium falciparum. Antimicrob Agents Chemother 1999, 43:1525-1527.

23. Kurth F, Pongratz $P$, Bélard $S$, Mordmüller B, Kremsner PG, Ramharter M: In vitro activity of pyronaridine against Plasmodium falciparum and comparative evaluation of anti-malarial drug susceptibility assays. Malar J 2009, 8:79

24. Pradines B, Tall A, Parzy D, Spiegel A, Fusai T, Hienne R, Trape JF, Doury JC: In vitro activity of pyronaridine and amodiaquine against African isolates (Senegal) of Plasmodium falciparum in comparison with standard antimalarial agents. J Antimicrob Chemother 1998, 42:333-339.

25. Pradines B, Mabika Mamfoumbi M, Parzy D, Owono Medang M, Lebeau C, Mourou Mbina JR, Doury JC, Kombila M: In vitro susceptibility of African isolates of Plasmodium falciparum from Gabon to pyronaridine. Am J Trop Med Hyg 1999, 60:105-108.

26. Pradines B, Tall A, Ramiandrasoa F, Spiegel A, Sokhna C, Fusai T, Mosnier J, Daries W, Trape JF, Kunesch G, Parzy D, Rogier C: In vitro activity of ironbinding compounds against Senegalese isolates of Plasmodium falciparum. J Antimicrob Chemother 2006, 57:1093-1099.

27. Price RN, Marfurt J, Chalfein F, Kenagalem E, Piera KA, Tjitra E, Anstey NM, Russel B: In vitro activity of pyronaridine against multidrug-resistant Plasmodium falciparum and Plasmodium viva. Antimicrob Agents Chemother 2010, 54:5146-5150.

28. Davis TM, Hamzah J, llett KF, Karunajeewa HA, Reeder JC, Batty KT, Hackett S, Barrett PHR: In vitro interactions between piperaquine, dihydroartemisinin, and other conventional and novel antimalarial drugs. Antimicrob Agents Chemother 2006, 50:2883-2885.

29. Vivas L, Rattray L, Stewart L, Bongard E, Robinson BL, Peters W, Croft SL: Anti-malarial efficacy of pyronaridine and artesunate in combination in vitro and in vivo. Acta Trop 2008, 105:222-228.

30. Ramharter M, Kurth F, Schreier AC, Nemeth J, Glasenapp I, Bélard S, Schlie M, Kammer J, Koumba PK, Cisse B, Mordmüller B, Lell B, Issifou S, Oeuvray C, Fleckenstein L, Kremsner PG: Fixed-dose pyronaridineartesunate combination for treatment of uncomplicated falciparum malaria in pediatric patients in Gabon. J Infect Dis 2008, 198:911-919.

31. Childs GE, Hausler B, Milhous W, Chen C, Wimonwattrawatee T, Pooyindee N, Boudreau EF: In vitro activity of pyronaridine against field isolates and reference clones of Plasmodium falciparum. Am J Trop Med Hyg 1988, 38:24-29.
32. Basco LK, Le Bras J: In vitro activity of pyronaridine against African strains of Plasmodium falciparum. Ann Trop Med Parasitol 1992, 86:447-454.

33. Pradines $B$, Bertaux $L$, Pomares $C$, Delaunay $P$, Marty P: Reduced in vitro susceptibility to artemisinin derivatives associated with multi-resistance in a traveller returning from South-East Asia. Malar J 2011, 10:268.

34. Davis TME, Hamzah J, Illett KF, Karunajeewa HA, Reeder JC, Batty KT, Hackett S, Barrett PHR: In vitro interactions between piperaquine, dihydroartemisinin, and other conventional and novel antimalarial drugs. Antimicrob Agents Chemother 2006, 50:2883-2885.

35. Fivelman QL, Adagu IS, Warhurst DC: Effects of piperaquine, chloroquine, and amodiaquine on drug uptake and of these in combination with dihydroartemisinin against drug-sensitive and -resistant Plasmodium falciparum strains. Antimicrob Agents Chemother 2007, 51:2265-2267.

36. Muangnoicharoen S, Johnson DJ, Looareesuwan S, Krudsood S, Ward SA: Role of known molecular markers of resistance in the antimalarial potency of piperaquine and dihydroartemisinin in vitro. Antimicrob Agents Chemother 2009, 53:1362-1366.

37. Snyder C, Chollet J, Santo-Tomas J, Scheurer C, Wittlin S: In vitro and in vivo interaction of synthetic peroxide RBx11160 (OZ277) with piperaquine in Plasmodium models. Exp Parasitol 2007, 115:296-300.

38. Tarning J, Ashley EA, Lindegardh N, Stepniewska K, Phaiphun L, Day NPJ, Mcgready R, Ashton M, Nosten F, White NJ: Population pharmacokinetics of piperaquine after two different treatment regimens with dihydroartemisinin-piperaquine in patients with Plasmodium falciparum malaria in Thailand. Antimicrob Agents Chemother 2008, 52:1052-1061.

39. Valecha N, Pyae Phyo A, Mayxay M, Newton PN, Krudsood S, Keomany S, Khanthavong $M$, Pongvongsa $T$, Ruangveerayuth $R$, uthaisil C, Ubben $D$, Duparc S, Bacchieri A, Corsi M, Rao BHK, Bhattacharya PC, Dubhashi N, Ghosh SK, Dev V, Kumar A, Pukittayakamee S: An open-label, randomized study of dihidroartemisinin-piperaquine versus artesunate-mefloquine for falciparum malaria in Asia. PloS One 2010, 5:11880.

40. Grande T, Bernasconi A, Erhart A, Gamboa D, Casapia M, Delgado C, Torres K, Fanello C, Llanos-Cuentas A, D'Alessandro U: A randomized controlled trial to assess the efficacy of dihydroartemisinin-piperaquine for the treatment of uncomplicated falciparum malaria in Peru. PLOS One 2007, 10:1101.

41. Awab GR, Pukrittayakamee S, Imwong M, Dondorp AM, Woodrow CJ, Lee SJ, Day NPJ, Singhasivanon P, White NJ, Kaker F: Dihydroartemisininpiperaquine versus chloroquine to treat vivax malaria in Afghanistan: an open randomized, non-inferiority, trial. Malar J 2010, 9:105.

42. Davis TM, Hung TY, Sim IK, Karunajeewa HA, Ilett KF: Piperaquine: a resurgent antimalarial drug. Drugs 2005, 65:75-87.

43. Briolant S, Henry M, Oeuvray C, Amalvict R, Baret E, Didillon E, Rogier C, Pradines $B$ : Absence of association between piperaquine in vitro responses and polymorphisms in the pfcrt, pfmdr1, pfmrp, and pfnhe genes in Plasmodium falciparum. Antimicrob Agents Chemother 2010, 54:3537-3544.

44. Basco LK, Ringwald P: In vitro activity of piperaquine and other 4aminoquinolines against clinical isolates of Plasmodium falciparum in Cameroon. Antimicrob Agents Chemother 2003, 47:1391-1394.

45. Barends M, Jaidee A, Khaohirun N, Singhasivanon P, Nosten F: In vitro activity of ferroquine (SSR 97193) against Plasmodium falciparum isolates from the Thai-Burmese border. Malar J 2007, 6:81.

46. Mwai L, Kiara SM, Abdirahman A, Pole L, Rippert A, Diriye A, Bull P, Marsh K, Borrmann S, Nzila A: In vitro activities of piperaquine, lumefantrine, and dihydroartemisinin in Kenyan Plasmodium falciparum isolates and polymorphisms in pfcrt and pfmdr1. Antimicrob Agents Chemother 2009, 55:5069-5073.

47. Nsobya SL, Kiggundu M, Nanyunja S, Joloba M, Greenhouse B, Rosenthal PJ: In vitro sensitivities of Plasmodium falciparum to different antimalarial drugs in Uganda. Antimicrob Agents Chemother 2010, 54:1200-1206.

48. Marfurt J, Chalfein F, Prayoga P, Wabiser F, Kenangalem E, Piear KA, MacHunter B, Tjitra E, Anstey NM, Price RN: Ex vivo drug susceptibility of ferroquine against chloroquine-resistant isolates of Plasmodium falciparum and P. vivax. Antimicrob Agents Chemother 2011, 55:4461-4464

49. Wong RP, Lautu D, Tavul L, Hackett SL, Siba P, Karunajeewa HA, llett KF, Mueller I, Davis TM: In vitro sensitivity of Plasmodium falciparum to conventional and novel antimalarial drugs in Papua New Guinea. Trop Med Int Health 2010, 15:342-349.

50. Eastman RT, Dharia NV, Winzeler EA, Fidock DA: Piperaquine resistance is associated with a copy number variation on chromosome 5 in drug- 
pressured Plasmodium falciparum parasites. Antimicrob Agents Chemother 2011, 55:3908-3916.

51. Myint HY, Ashley EA, Day NPJ, Nosten F, White NJ: Efficacy and safety of dihydroartemisinin-piperaquine. Trans R Soc Trop Med Hyg 2007, 101:858-866.

52. Price RN, Hasugian AR, Ratcliff A, Siswantoro H, Purba HLE, Kenangalem E, Lindegardh N, Penttinen P, Laihad F, Ebsworth EP, Anstey NM, Tjitra E:

Clinical and pharmacological determinants of the therapeutic response to dihydroartemisinin-piperaquine for drug-resistant malaria. Antimicrob Agents Chemother 2007, 51:4090-4097.

53. Kamya MR, Yeka A, Burkirwa H, Lugemwa M, Rwakimari JB, Staedke SG, Talisuna AO, Greenhouse B, Nosten F, Rosenthal PJ, Wabwire-Mangen F, Dorsey G: Artemether-lumefantrine versus dihydroartemisininpiperaquine for treatment of malaria: a randomized trial. Plos Clin Trials 2007, 2:20.

54. Zongo I, Dorsey G, Rouamba N, Dokomajilar C, Séré Y, Rosenthal PJ, Ouédraogo JB: Randomized comparison of amodiaquine plus sulfadoxine-pyrimethamine, artemether-lumefantrine, and dihydroartemisinin-piperaquine for the treatment of uncomplicated Plasmodium falciparum malaria in Burkina-Faso. Clin Infect Dis 2007, 45:1453-1461.

55. Hasugian AR, Purba HLE, Kenangalem E, Wuwung RM, Ebsworth EP, Maristela R, Penttinen PMP, Laihad F, Anstey NM, Tjitra E, Price RN: Dihydroartemisinin-piperaquine versus artesunate-amodiaquine: superior efficacy and posttreatment prophylaxis against multidrug resistant Plasmodium falciparum and Plasmodium viva malaria. Clin Infect Dis 2008, 44:1067-1074.

56. Karunajeewa HA, llett KF, Mueller I, Siba P, Law I, Page-Sharp M, Lin E, Lammey J, Batty KT, Davis TME: Pharmacokinetics and efficacy of piperaquine and chloroquine in Melanesian children with uncomplicated malaria. Antimicrob Agents Chemother 2008, 52:237-243.

57. Tarning J, Lindegardh N, Annerberg A, Singtoroj T, Day NPJ, Ashton M, White NJ: Pitfalls in estimating piperaquine elimination. Antimicrob Agents Chemother 2005, 49:5127-5128.

58. Ezzet F, Mull R, Karbwang J: Population pharmacokinetics and therapeutic response of CGP 56697 (artemether + benflumetol) in malaria patients. Br J Clin Pharmacol 1998, 46:553-561.

doi:10.1186/1475-2875-11-45

Cite this article as: Pascual et al:: Ex vivo activity of the ACT new components pyronaridine and piperaquine in comparison with conventional ACT drugs against isolates of Plasmodium falciparum. Malaria Journal 2012 11:45.

\section{Submit your next manuscript to BioMed Central and take full advantage of:}

- Convenient online submission

- Thorough peer review

- No space constraints or color figure charges

- Immediate publication on acceptance

- Inclusion in PubMed, CAS, Scopus and Google Scholar

- Research which is freely available for redistribution

Submit your manuscript at www.biomedcentral.com/submit
Biomed Central 